\title{
One-Year Outcomes Using Ranibizumab for Neovascular Age-Related Macular Degeneration: Results of a Prospective and Retrospective Observational Multicentre Study
}

\author{
Lars Hjelmqvist, ${ }^{1}$ Charlotte Lindberg, ${ }^{2,3}$ Pär Kanulf, ${ }^{4}$ Henrik Dahlgren, ${ }^{5}$ \\ Ingrid Johansson, ${ }^{6}$ and Annica Siewert ${ }^{7}$
}

${ }^{1}$ St. Erik's Eye Hospital, Karolinska Institutet, Polhemsgatan 50, 11282 Stockholm, Sweden

${ }^{2}$ Department of Ophthalmology, Lund University Hospital, 22185 Lund, Sweden

${ }^{3}$ Department of Ophthalmology, Helsingborg Hospital, 25187 Helsingborg, Sweden

${ }^{4}$ Department of Ophthalmology, Ryhov Hospital, 55185 Jönköping, Sweden

${ }^{5}$ Department of Ophthalmology, Södersjukhuset, 11883 Stockholm, Sweden

${ }^{6}$ Department of Ophthalmology, Örebro University Hospital, 70185 Örebro, Sweden

${ }^{7}$ Medical Department, Novartis Sweden AB, 18311 Täby, Sweden

Correspondence should be addressed to Lars Hjelmqvist, lars.hjelmqvist@sankterik.se

Received 3 August 2011; Accepted 7 September 2011

Academic Editor: G. L. Spaeth

Copyright (C) 2011 Lars Hjelmqvist et al. This is an open access article distributed under the Creative Commons Attribution License, which permits unrestricted use, distribution, and reproduction in any medium, provided the original work is properly cited.

The Swedish Lucentis Quality Registry is a 12-month, open-label, observational, prospective, and retrospective study of ranibizumab administration for wet AMD. Visual acuity (VA) was measured with Snellen or ETDRS chart in 370 patients (66.8\% women; age range 46-93 years). In total, a mean of $4.7 \pm 1.6$ injections per patient (range 1-10) was given to month 12 . Mean VA score was $58.3 \pm 12.2$ letters before treatment, $63.3 \pm 12.5$ after 3 injections $(\Delta 4.9 \pm 10.1$ letters from baseline $)$, and $59.3 \pm 16.2$ at 12 months $(\Delta 1.0 \pm 13.6)$. VA score from baseline to month 12 was stable in $74.4 \%$ of patients, improved by 15 letters $/ 3$ lines or more in $14.7 \%$, and decreased by $\geq 15$ letters $/ 3$ lines in $10.9 \%$ of patients. With a mean of 4.7 ranibizumab injections per patient per year, mean VA was stabilised but not increased. To maintain the initial gain seen after the first three injections, an average of $1.8 \pm 1.5$ additional injections does not appear to be adequate.

\section{Introduction}

As the population ages, establishing effective treatment strategies for age-related macular degeneration (AMD) becomes increasingly important. AMD is the leading cause of irreversible blindness in patients over the age of 50 [13 ], with an incidence that rises from $0.2 \%$ in those aged 5564 to $13 \%$ after the age of 85 [4]. The neovascular form of AMD, characterised by choroidal neovascularisation and proliferation of fibrous tissue, represents only $10-15 \%$ of cases but is responsible for more than $80 \%$ of AMD-related severe visual loss or blindness [5].

Management of neovascular AMD centres on intravitreal antiangiogenic therapy, which localises therapy to the eye and avoids systemic exposure. Following limited success with pegaptanib, the first licensed intravitreal agent for neovascular AMD [6], ranibizumab, became available in 2006. Ranibizumab is an antivascular endothelial growth factor (VEGF) antibody fragment which binds to VEGF and inhibits the contribution of VEGF to the formation of neovascular lesions in the choroid [7]. Two pivotal trials in which ranibizumab was injected intravitreally once a month, one placebo-controlled and the other using Photodynamic Therapy (PDT) as the control, both showed a remarkable improvement in visual acuity (VA) from baseline in treated eyes, as measured by the Early Treatment Diabetic Retinopathy Study (ETDRS) chart $[8,9]$. On the basis of these results, ranibizumab is now recommended as a first-line therapy [10] and is the most widely prescribed treatment for neovascular AMD. 
Nevertheless, there remain unanswered questions about the optimal evaluation and treatment regimen for ranibizumab that balances VA improvement in the individual patient versus logistical and cost issues. Recommendations for the use of ranibizumab have been developed which point out that continued monthly injections offer the best VA outcomes but that if regular monthly administration is not feasible then flexible retreatment after three monthly injections is viable [11]. In practice, however, the current consensus is that after the first three injections, monthly maintenance visits with clinician-determined retreatment are appropriate $[10,12]$. Evidence concerning the efficacy of administering ranibizumab as needed based on monthly evaluation by clinical findings or imaging is growing, with two small, nonrandomised prospective studies $[13,14]$, a series of retrospective analyses [15-21] and most recently a large multicentre, single-blind trial [22].

As part of an ongoing pharmacovigilance program for ranibizumab, Novartis Pharma AG (Basel, Switzerland) has initiated the LUMINOUS program designed to assess longterm safety, efficacy, treatment patterns, and health-related quality of life outcomes in a large number of patients treated with ranibizumab in routine clinical practice across the world. We report here the findings from the Swedish Lucentis Quality Registry, which records efficacy and safety results following ranibizumab administration according to local practice in patients with AMD at five specialist centres. The aim of the registry is to understand how ranibizumab is being deployed in routine practice outside the setting of a clinical trial, and to establish what improvement in VA can be achieved and the number of injections and visits needed. The current paper addresses the following objectives of the registry: (i) to characterise the population of patients receiving ranibizumab, (ii) to record the number of injections administered and the dosing frequency, (iii) to evaluate the effect of ranibizumab treatment on VA, and (iv) to characterise, describe, and evaluate side effects. Data collected up to January 2011 are presented.

\section{Methods}

2.1. Study Design. The Swedish Lucentis Quality Registry is a 12-month, open-label, observational, noncomparative study that is ongoing at five specialist centres in Sweden. These clinics were chosen since they were among the first to implement intravitreal ranibizumab treatment for wet AMD in Sweden. Outpatients who were receiving ranibizumab at the time the study started (retrospective component) or with whom the decision was subsequently made to start treatment with ranibizumab (prospective component) were eligible for inclusion unless they were receiving the drug within a controlled clinical trial. Ranibizumab treatment is administered according to the approved label, that is, three initial injections and then according to need based on VA, optical coherence tomography (OCT) findings, and the investigator's judgment. The assessments performed and the criteria applied at each centre to initiate treatment or reinjection were not recorded. Standard single-use ranibizumab vials (containing $0.23 \mathrm{~mL}$ ranibizumab $10 \mathrm{mg} / \mathrm{mL}$ ) are used.
Retrospective data were collected from patients who started ranibizumab during the period from July 2007 to March 2008. The prospective component was initiated in April 2008, when the registry was opened, with recruitment ending in December 2009. Written, informed consent was obtained from all participants following ethical approval from the Regional Ethical Review Board in Stockholm.

2.2. Evaluation and Data Collection. All clinical assessments are performed at the discretion of the investigator as per local practice. Data are recorded at every monthly visit during the first 12 months of treatment. For both retrospectively and prospectively included patients, the visits that took place closest to these times were used for evaluation. Retrospective data were obtained from patients' medical records. Prospective data are collected at study entry (i.e., the date of first ranibizumab injection) and during the following year, in accordance with the local visit schedule.

The following data are obtained at baseline and at all routine visits during the first year of ranibizumab treatment: patient age and gender (baseline only); indication for use of ranibizumab; cause of treatment discontinuation prior to the end of the 12-month observation, if applicable; number, timing, and frequency of ranibizumab doses administered during the first 12 months of treatment; whether OCT was or was not performed at baseline; VA prior to treatment and at all visits (except at the second and third injection visits when VA was not always measured) during the first 12 months of treatment as assessed by the ETDRS chart and adverse events since study entry. In addition, visionrelated function as measured by The National Eye Institute Visual Function Questionnaire-25 (VFQ-25) is recorded at study entry, 3 months and 12 months in the prospectively recruited patients. VFQ-25 subscales were calculated as per the recommended procedure [23]. Each item was converted to a 0-to-100 scale where higher scores represent better functioning. Items within a subscale were averaged and the score represents the average for all items in the subscale. The overall score was averaged over all subscales, excluding the general health item, and thus equal weight was given to each subscale.

All data are entered online by the clinical team at each centre to a password-protected web-based data system. Access to individual patient data is only available to the local clinical team. All participating centres have online access to pooled data in real time from their own centre and from the total patient population.

2.3. Data Analysis. Assessment of efficacy is based on VA measurements (ETDRS chart scores) before and after treatment. In 100 of the retrospective patients, Snellen VA testing was used at baseline. In order to use these data, the Snellen value was recalculated to determine the corresponding ETDRS value using a formula that reflects the relationship between the two methods:

$$
\text { ETDRS (number of letters) }=50^{*} \log _{10}\left(\frac{\text { Snellen }}{100}\right)+36 \text {. }
$$


VA measurements are presented as absolute values (mean \pm standard deviation $[\mathrm{SD}]$ ), as a mean change from baseline to month 12 (mean \pm standard error [SEM]), and in terms of the number of patients with (i) a gain of $\geq 15$ letters or 3 lines, (ii) a change of $<15$ letters or 3 lines, or (iii) a loss of $\geq 15$ letters or 3 lines.

The VFQ-25 subscales are not strictly ordinal or equal interval measures, but because they approximate intervallevel measures, mean and standard deviations were computed [24]. Change from baseline to 3 and 12 months was tested with Wilcoxon signed rank test. Since the probability of making type 1 error increases with the number of analytical tests performed, care should be taken when interpreting the results.

Safety assessment was based on the frequency of adverse events and serious adverse events. Adverse events were categorised by severity (mild, moderate, or severe), relationship to ranibizumab (probable, possible, or unlikely), and whether they constituted a serious adverse event.

Data are presented for the on-treatment population, comprising all intent-to-treat (ITT) patients in whom treatment/followup visits were not discontinued during the oneyear study period. All data are presented descriptively.

It was anticipated that retrospective data from approximately 200 patients would be available, with prospective data from a further 200 patients. No sample size calculation was required since no statistical hypothesis was tested.

The study database and electronic data capture were managed by Pharma Consulting Group AB, Uppsala, Sweden. Data analysis was undertaken by the Pharma Consulting Group using the SAS system version 9.2 (SAS Institute Inc, Cary, NC, USA).

\section{Results}

3.1. Patient Population. In total, 475 patients were enrolled in the registry, of whom 471 received at least one dose of ranibizumab and formed the ITT population. Two hundred and seventy-two patients were enrolled retrospectively [57.7\%] and 199 prospectively [42.3\%]. Of these, 370 patients were followed for one year without discontinuing ranibizumab treatment/followup visits (the "on-treatment" population; retrospective 206 [55.7\%], prospective 164 [44.3\%]). In total, $101 / 471$ patients (21.4\%) discontinued before one year. In approximately a third of these cases $(n=$ 34 ), this was due to the treating physician's decision that no further followup was required (Table 1). The 43 patients who discontinued for "other reasons" did so for a variety of causes, the most frequent being VA was too low $(n=17)$, lack of VA improvement $(n=3)$, nonattendance at followup visits $(n=7)$, change in therapy $(n=6)$, death $(n=5)$, and various reasons $(n=5)$. There were no marked differences between the ITT and on-treatment populations in terms of demographics or baseline characteristics (Table 1).

Two-thirds of the population were female, and the mean age at entry was 78 years (Table 1). Ranibizumab injections were evenly divided between left and right eyes $(52.7 \%$ and $47.3 \%$, resp.). The mean number of visits during the first year of treatment in the on-treatment population, irrespective of

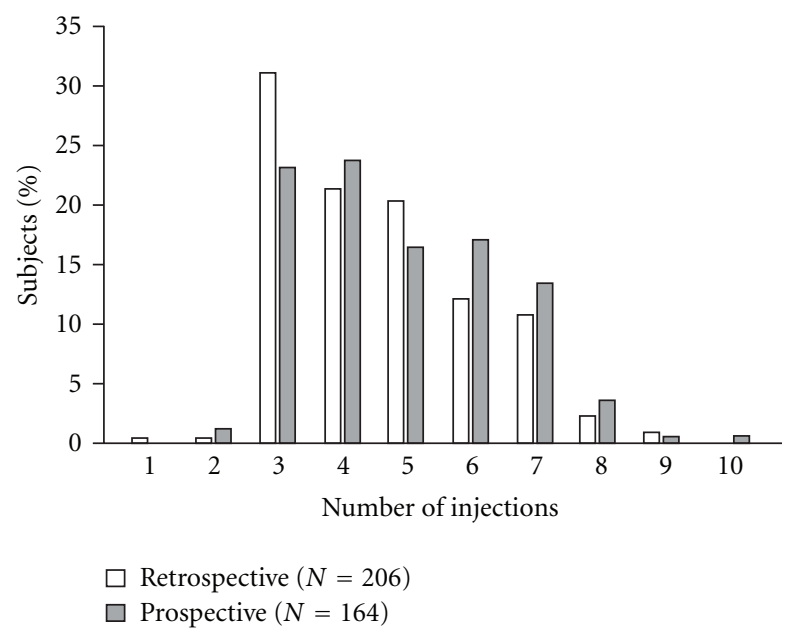

Figure 1: Number of ranibizumab injections received during year 1 in the retrospectively and prospectively recruited subpopulations (on-treatment population, $n=370$ ).

whether ranibizumab was injected, was $9.4 \pm 1.8$, ranging from 4 to 13 visits. The last visit at which VA was assessed occurred at months $7,8,9,10,11,12$, and 13 in 1, 6, 22, 27, 50,262 , and 2 patients, respectively.

3.2. Ranibizumab Therapy. All three initial ranibizumab injections were administered to $95.1 \%(352 / 370)$ in the ontreatment population. The mean number of ranibizumab injections was $4.7 \pm 1.6$ (mean $1.8 \pm 1.5$ after the three initial injections). The number of injections in the on-treatment population was similar in the retrospective subpopulation (mean $4.6 \pm 1.5 ; 197 / 206$ [95.6\%] received all three initial injections) and the prospective subpopulation (mean $4.9 \pm$ $1.6 ; 155 / 164[94.5 \%])$. The majority of patients received three $(27.6 \%, n=102)$, four $(22.4 \%, n=83)$, or five $(18.6 \%, n=69)$ injections, with a slightly higher proportion of prospectively enrolled patients receiving more than three injections than in the earlier, retrospective cohort (Figure 1). There was no correlation between VA at baseline and the number of ranibizumab injections given (data not shown).

3.3. Visual Acuity. The mean VA score at baseline was $58.3 \pm$ 12.2 letters (on-treatment population) and was similar in the retrospective and prospective subpopulations $(58.2 \pm 12.0$ letters and $58.4 \pm 12.3$ letters, resp.). At month 12 , the mean VA score was $59.3 \pm 16.2$ letters, an increase of $1.0 \pm$ 13.6 versus baseline. The maximum improvement was seen at month 3 following administration of three ranibizumab injections, when mean VA score peaked at $63.3 \pm 12.5$ letters, a mean increase of $4.9 \pm 10.1$ from baseline. After month 3, the mean VA score progressively declined back to baseline levels (Figure 2). The mean improvement in VA score from baseline to month 12 was greater in younger patients and in females (Table 2). There was no consistent association between improvement in VA score and the number of injections administered.

The majority of patients $(74.4 \%)$ showed a stable score over the 12-month period, defined as a change of $<15$ 
TABLE 1: Baseline characteristics and ranibizumab treatment.

\begin{tabular}{|c|c|c|}
\hline & $\begin{array}{l}\text { ITT population } \\
\quad(n=471) \\
\end{array}$ & $\begin{array}{l}\text { On-treatment population } \\
\qquad(n=370)\end{array}$ \\
\hline \multicolumn{3}{|l|}{ Baseline age (years) } \\
\hline Mean \pm SD & $78.1 \pm 8.0$ & $77.7 \pm 8.0$ \\
\hline Range & $46-93$ & $46-93$ \\
\hline \multicolumn{3}{|l|}{ Gender, $n(\%)$} \\
\hline Male & $160(34.0 \%)$ & $123(33.2 \%)$ \\
\hline Female & $311(66.0 \%)$ & $247(66.8 \%)$ \\
\hline \multicolumn{3}{|l|}{ Indication for ranibizumab, $n(\%)$} \\
\hline Wet AMD & $468(99.4 \%)$ & $368(99.5 \%)$ \\
\hline Other & $3(0.6 \%)$ & $2(0.5 \%)$ \\
\hline \multicolumn{3}{|l|}{ Baseline OCT performed, $n(\%)$} \\
\hline Yes & $357(75 \%)$ & $242(75 \%)$ \\
\hline No & $115(24 \%)$ & $82(25 \%)$ \\
\hline Unknown & $2(0.4 \%)$ & 0 \\
\hline \multicolumn{3}{|l|}{ Baseline ETDRS, $n(\%)$} \\
\hline Yes & $337(71 \%)$ & $223(69 \%)$ \\
\hline No & $136(28.6 \%)$ & $101(31 \%)$ \\
\hline Unknown & $2(0.4 \%)$ & 0 \\
\hline \multicolumn{3}{|l|}{ Initial 3 ranibizumab injections, $n(\%)$} \\
\hline \multicolumn{3}{|l|}{ No } \\
\hline 1 & $11(2.3 \%)$ & $3(0.8 \%)$ \\
\hline 2 & $25(5.3 \%)$ & $15(4.1 \%)$ \\
\hline Yes & $435(92.4 \%)$ & $352(95.1 \%)$ \\
\hline Total number of ranibizumab injections & ( $\leq 12$ months $)$ & (12 months) \\
\hline Mean \pm SD & $4.4 \pm 1.6$ & $4.7 \pm 1.6$ \\
\hline Range & $0-10$ & $1-10$ \\
\hline Number of visits & ( $\leq 12$ months $)$ & (12 months) \\
\hline Mean \pm SD & $9.4 \pm 2.6$ & $10.3 \pm 1.8$ \\
\hline Range & $1-14$ & $5-14$ \\
\hline Discontinuation before month $12, n(\%)$ & $101(21.4 \%)$ & \\
\hline \multicolumn{3}{|l|}{ Reason for discontinuation, $n(\%)$} \\
\hline Withdrawal of informed consent & $2(0.4 \%)$ & - \\
\hline Decline further injections & $6(1.2 \%)$ & - \\
\hline Serious complication & $1(0.2 \%)$ & - \\
\hline Retinal detachment & 0 & - \\
\hline Referred for continuous follow up & $7(1.5 \%)$ & - \\
\hline Physician's decision that no further & $34(7.2 \%)$ & - \\
\hline \multicolumn{3}{|l|}{ followup is necessary } \\
\hline Other reason & $43(9.1 \%)$ & - \\
\hline Unknown & $8(1.7 \%)$ & - \\
\hline
\end{tabular}

letters/3 lines. In total, $14.7 \%(n=54)$ had improved by 15 letters/3 lines or more, while $10.9 \%$ of patients $(n=40)$ had lost $\geq 15$ letters $/ 3$ lines (Table 2 ).

3.4. Vision-Related Function (VFQ-25). The increase in VA at month 3 was accompanied by a significant improvement in VFQ-25 total score from baseline, as recorded in 131 of the prospectively recruited patients (Table 3 ). Several VFQ25 subscales, including general vision, ocular pain, and both near and distance activities, also improved significantly. By month 12, the general vision, near activities, and driving subscales were significantly higher compared to baseline, but total VFQ-25 score had returned to near-baseline levels.

3.5. Safety and Tolerability. In the ITT population, that is, all patients who received one or more ranibizumab injection, a total of 17 adverse events occurred in 16 patients during followup $(16 / 471[3.4 \%])$. Of these, eight were graded 
TABLE 2: Change in VA score from baseline to last visit (on-treatment population, $n=370^{\dagger}$ ).

\begin{tabular}{|c|c|c|c|c|c|c|}
\hline & $\begin{array}{l}\mathrm{VA} \text { at baseline } \\
\text { mean } \pm \mathrm{SD} \\
\text { median (range) }\end{array}$ & $\begin{array}{l}\mathrm{VA} \text { at last visit } \\
\text { mean } \pm \mathrm{SD} \\
\text { median (range) }\end{array}$ & $\begin{array}{c}\text { Change from } \\
\text { baseline to last visit } \\
\text { mean } \pm \text { SD } \\
\text { median (range) }\end{array}$ & $\begin{array}{c}\text { Improved } \\
\text { (change } \geq 15 \\
\text { letters/3 lines) } \\
N(\%)\end{array}$ & $\begin{array}{c}\text { Stable } \\
\text { (change }<15 \\
\text { letters/3 lines) } \\
N(\%) \\
\end{array}$ & $\begin{array}{c}\begin{array}{c}\text { Deterioration } \\
\text { (change } \geq 15\end{array} \\
\text { letters } / 3 \text { lines) } \\
N(\%)\end{array}$ \\
\hline All patients & $\begin{array}{l}58.3 \pm 12.2 \\
60(7-86)\end{array}$ & $\begin{array}{c}59.3 \pm 16.2 \\
61(1-90)\end{array}$ & $\begin{array}{c}1.0 \pm 13.6 \\
1(-38-56)\end{array}$ & $54(14.7 \%)$ & $273(74.4 \%)$ & $40(10.9 \%)$ \\
\hline$<80$ years $(N=195)$ & $\begin{array}{l}59.6 \pm 11.1 \\
60(30-85)\end{array}$ & $\begin{array}{l}61.6 \pm 14.8 \\
63(16-90)\end{array}$ & $\begin{array}{c}2.1 \pm 12.8 \\
3(-37-36)\end{array}$ & $33(16.9 \%)$ & $146(74.9 \%)$ & $16(8.2 \%)$ \\
\hline$\geq 80$ years $(N=172)$ & $\begin{array}{c}56.8 \pm 13.1 \\
60(7-86) \\
\end{array}$ & $\begin{array}{c}56.6 \pm 17.3 \\
59(1-88)\end{array}$ & $\begin{array}{l}-0.2 \pm 14.5 \\
0(-38-56)\end{array}$ & $21(12.2 \%)$ & $127(73.8 \%)$ & $24(14.0 \%)$ \\
\hline Female $(N=245)$ & $\begin{array}{l}58.5 \pm 11.6 \\
60(17-86)\end{array}$ & $\begin{array}{c}60.3 \pm 14.8 \\
62(1-88)\end{array}$ & $\begin{array}{c}1.9 \pm 12.4 \\
3(-38-39)\end{array}$ & $35(14.3 \%)$ & $190(77.6 \%)$ & $20(8.2 \%)$ \\
\hline Male $(N=122)$ & $\begin{array}{c}57.9 \pm 13.2 \\
60(7-85) \\
\end{array}$ & $\begin{array}{c}57.2 \pm 18.7 \\
60(5-90) \\
\end{array}$ & $\begin{array}{l}-0.7 \pm 15.7 \\
0(-38-56)\end{array}$ & $19(15.6 \%)$ & $83(68.0 \%)$ & $20(16.4 \%)$ \\
\hline $\begin{array}{l}\text { Baseline VA } \leq \text { median } \\
(N=179)\end{array}$ & $\begin{array}{l}48.2 \pm 8.3 \\
50(7-59)\end{array}$ & $\begin{array}{c}51.8 \pm 16.2 \\
53(1-83)\end{array}$ & $\begin{array}{c}3.5 \pm 15.2 \\
4(-37-56)\end{array}$ & $40(22.3 \%)$ & $120(67.0 \%)$ & $19(10.6 \%)$ \\
\hline $\begin{array}{l}\text { Baseline VA > median } \\
(N=188)\end{array}$ & $\begin{array}{l}67.8 \pm 6.0 \\
67(60-86)\end{array}$ & $\begin{array}{l}66.4 \pm 12.7 \\
69(23-90)\end{array}$ & $\begin{array}{l}-1.4 \pm 11.5 \\
-1(-38-21)\end{array}$ & $14(7.4 \%)$ & $153(81.4 \%)$ & $21(11.2 \%)$ \\
\hline $\begin{array}{l}\text { Retrospectively recruited } \\
(N=203)\end{array}$ & $\begin{array}{c}58.2 \pm 12.0 \\
60(7-86)\end{array}$ & $\begin{array}{c}60.1 \pm 15.6 \\
61(5-88)\end{array}$ & $\begin{array}{c}1.9 \pm 13.5 \\
2(-37-56)\end{array}$ & $32(15.8 \%)$ & $153(75.4 \%)$ & $18(8.9 \%)$ \\
\hline $\begin{array}{l}\text { Prospectively recruited } \\
(N=164)\end{array}$ & $\begin{array}{l}58.4 \pm 12.3 \\
60(21-84)\end{array}$ & $\begin{array}{c}58.3 \pm 17.0 \\
61(1-90)\end{array}$ & $\begin{array}{c}-0.1 \pm 13.7 \\
0.5(-38-33)\end{array}$ & $22(13.4 \%)$ & $120(73.2 \%)$ & $22(13.4 \%)$ \\
\hline
\end{tabular}

${ }^{\dagger}$ Data not available for 3 patients.

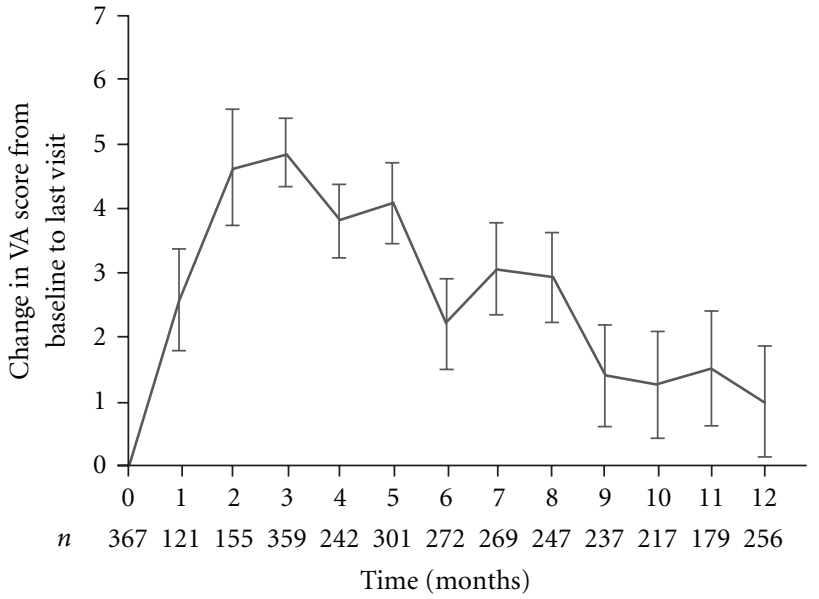

FIGURE 2: Change in VA score (ETDRS chart) from baseline (BL) to month 12 (on-treatment population, $n=370$ ). Values are shown as mean \pm SEM.

mild (pain (2), conjunctivitis (2), retinal pigment epithelial tear, conjunctival haemorrhage, blepharal papilloma, and transient ischaemic attack), four moderate (retinal pigment epithelial tear (2), angina pectoris, and cardiac failure), and four severe (duodenal ulcer haemorrhage, cerebrovascular accident, mesothelioma, and death). The treating physician considered there to be a probable relation to ranibizumab in two cases (mild conjunctival haemorrhage that did not require treatment and retinal pigment epithelial tear in a patient with very low VA before treatment and after one injection the treatment was stopped due to low vision), and a possible relation in five cases: mild pain (2), cerebrovascular accident, transient ischaemic attack, and retinal pigment epithelial tear (following which ranibizumab treatment was temporarily stopped). There were four deaths during the study, none reported as related to the treatment.

\section{Discussion}

The Swedish Lucentis Quality Registry provides a large database relating to clinical experience with ranibizumab treatment for neovascular AMD, for which almost half the patients were recruited prospectively. In this cohort of 370 patients followed for one year at five centres, almost all patients (95\%) received three initial monthly injections as per the product license, with an average of 1.8 subsequent injections. The improvement in VA following the initial three injections (mean 4.9 letters) was somewhat lower than that observed in the pivotal MARINA [8] and ANCHOR [25] trials ( $\sim 6$ and $\sim 10$ letters, resp.). With the current treatment pattern, this benefit was not sustained: the VA score at month 12 was similar to baseline.

However, a higher rate of subsequent ranibizumab injections could be expected to have sustained the initial improvement in VA seen after the first three administrations. VEGF level has been shown to correlate with the extent of macular oedema [26], and while the decrease in VEGF level observed following intravitreal injection of ranibizumab is lost after four weeks it is prolonged by retreatment [26]. In the 24-month MARINA [8] and ANCHOR $[9,25]$ studies, a fixed monthly schedule of ranibizumab showed sustained benefits to the end of each trial. In an attempt to minimise the number of injections administered, a quarterly ranibizumab treatment regimen has been investigated in randomised studies [27-30] but using this approach the sustained 
TABLE 3: VFQ-25 subscale and total scores at 3 and 12 months. Values are shown as mean \pm SD.

\begin{tabular}{|c|c|c|c|c|c|c|c|c|}
\hline \multirow{2}{*}{ Subscale } & \multicolumn{4}{|c|}{ Month 3} & \multicolumn{4}{|c|}{ Month 12} \\
\hline & $n$ & Baseline & Month 3 & $P$-value ${ }^{\dagger}$ & $n$ & Baseline & Month 12 & $P$-value ${ }^{\dagger}$ \\
\hline General health & 130 & $52.5 \pm 21.8$ & $51.9 \pm 20.6$ & 0.718 & 89 & $53.9 \pm 23.5$ & $52.0 \pm 23.0$ & 0.404 \\
\hline General vision & 129 & $51.0 \pm 19.8$ & $59.2 \pm 18.3$ & $<0.001$ & 89 & $52.1 \pm 19.7$ & $60.2 \pm 18.7$ & $<0.001$ \\
\hline Ocular pain & 131 & $80.0 \pm 21.8$ & $85.0 \pm 17.6$ & 0.001 & 91 & $81.7 \pm 21.1$ & $85.7 \pm 17.0$ & 0.081 \\
\hline Near activities & 131 & $58.9 \pm 18.7$ & $63.2 \pm 19.0$ & $<0.001$ & 91 & $60.2 \pm 18.6$ & $64.3 \pm 19.7$ & 0.029 \\
\hline Distance activities & 131 & $64.4 \pm 20.3$ & $66.7 \pm 20.1$ & 0.026 & 91 & $66.8 \pm 18.8$ & $68.1 \pm 20.1$ & 0.435 \\
\hline \multicolumn{9}{|l|}{ Vision specific: } \\
\hline Social functioning & 130 & $79.5 \pm 21.8$ & $80.9 \pm 19.8$ & 0.213 & 90 & $82.1 \pm 19.7$ & $82.0 \pm 18.5$ & 0.760 \\
\hline Mental health & 131 & $59.6 \pm 28.7$ & $65.7 \pm 27.9$ & $<0.001$ & 91 & $61.9 \pm 27.3$ & $66.0 \pm 28.3$ & 0.055 \\
\hline Role difficulties & 129 & $61.7 \pm 29.5$ & $62.7 \pm 29.3$ & 0.720 & 89 & $64.9 \pm 28.7$ & $63.8 \pm 28.6$ & 0.636 \\
\hline Dependency & 128 & $74.8 \pm 31.7$ & $75.6 \pm 31.6$ & 0.439 & 89 & $79.6 \pm 30.5$ & $75.8 \pm 31.7$ & 0.152 \\
\hline Driving & 65 & $60.7 \pm 33.8$ & $61.1 \pm 35.6$ & 0.897 & 47 & $63.3 \pm 30.2$ & $57.6 \pm 31.8$ & 0.044 \\
\hline Colour vision & 124 & $82.9 \pm 19.9$ & $83.7 \pm 20.1$ & 0.568 & 86 & $83.5 \pm 18.7$ & $81.9 \pm 19.1$ & 0.328 \\
\hline Peripheral vision & 125 & $70.6 \pm 20.6$ & $72.3 \pm 21.1$ & 0.153 & 85 & $72.2 \pm 19.0$ & $72.2 \pm 21.2$ & 0.884 \\
\hline VFQ-25 total & 131 & $67.4 \pm 19.3$ & $70.6 \pm 19.0$ & $<0.001$ & 91 & $69.9 \pm 17.8$ & $70.9 \pm 18.4$ & 0.389 \\
\hline
\end{tabular}

${ }^{\dagger}$ Wilcoxon signed rank test.

improvement in VA achieved with three monthly injections was lost. An individualised dosing strategy has been explored in a small nonrandomised, open-label trial (PrONTO) [13] which employed three initial monthly injections of ranibizumab with subsequent injections performed based on the evolution of VA and the presence or absence of subfoveal fluid, as detected by OCT. The mean VA improvement described in the PrONTO study was similar to that seen in the MARINA and ANCHOR trials, but required an average of 5.6 injections over the first year [13], with the improvement maintained at two years [31]. Another nonrandomised prospective study, in which patients received a mean of 5.1 clinically determined ranibizumab injections over 12 months, with a single application of reduced fluence photodynamic therapy, reported a mean VA improvement of 7.2 letters at month 12 [14]. Other recent studies have demonstrated a higher response as the number of injections increases [21,32]. The most conclusive evidence comes from the recent CATT trial, a large randomised study in which ranibizumab given monthly or as needed was compared to bevacizumab, again administered monthly or as needed on the basis of monthly evaluations [22]. Results showed that the efficacy of ranibizumab at one year, as measured by improvement in VA, was similar with either monthly or individualised dosing, with the individualised group receiving a mean of 6.9 injections by month 12 . In our observational study, a mean of 4.7 injections resulted in stable VA with no long-term improvement although elsewhere an individualised, clinically driven approach to reinjection has demonstrated good results obtained with a mean of $>5$ reinjections after the initial three-injection regimen $[29,33$, 34]. It appears that the number of reinjections may be critical in maintaining early increase in VA and that fewer than 5 injections during the first year appear inadequate.

No marked difference in the change in VA score was observed between the retrospective and prospective subpopulations (to be confirmed), although slightly more prospectively recruited patients received $>3$ injections. One hundred of the 272 patients in the retrospective population had baseline VA measured by Snellen scoring, requiring conversion to EDTRS values. The two scoring systems are known to show differences, particularly in patients with wet AMD and poor VA [35], but the similarity of VA score at baseline in the retrospective cohort (including patients converted from Snellen scores) and the prospective arm suggests that this was not an important source of bias.

The change in VA score over the 12-month followup period was mirrored in the observed change in vision-related function. A significant improvement in VFQ-25 total score was achieved at month 3 but declined to near-baseline levels by month 12 . Certain subscale scores remained significant at month 12 , including general vision and near activities, but the relatively small number of patients $(\sim 90)$ and the subjective nature of scales of this type mean that this should be interpreted with caution when the improvement in the more robust endpoint of VA score was not maintained to month 12.

Regarding safety, intravitreal ranibizumab has previously been established as a safe and well-tolerated therapy for neovascular AMD [36]. In our population of 471 patients, there were only two adverse events with a probable relation to ranibizumab (a mild conjunctival haemorrhage and a pigment epithelium rift) over the 12-month study period, with a possible relation in a further five cases. No patient discontinued treatment due to adverse events. This safety profile is consistent with the extremely low systemic exposure to ranibizumab observed following intravitreal administration and the short half-life of the drug [37, 38], which minimises the risk of systemic anti-VEGF adverse events.

\section{Conclusion}

The findings from this large cohort of retrospectively and prospectively recruited patients indicate that an individualised approach, whereby three monthly initial injections are 
followed by additional injections as determined by OCT or clinical monitoring, can maintain VA at long-term baseline levels. To sustain the short-term improvement seen after the initial injection schedule, however, requires more than the mean of 1.8 repeat injections administered in this population. The observational nature of the study does not, however, permit specific recommendations on the optimal number or frequency of injections or the indications for reinjection.

\section{Conflict of Interests}

A. Siewert is an employee of Novartis. The other authors have no conflict of interests to declare.

\section{Acknowledgment}

The Swedish Lucentis Quality Registry is funded by Novartis Sweden AB.

\section{References}

[1] D. Pascolini, S. P. Mariotti, G. P. Pokharel et al., "2002 Global update of available data on visual impairment: a compilation of population-based prevalence studies," Ophthalmic Epidemiology, vol. 11, no. 2, pp. 67-115, 2004.

[2] N. Congdon, B. O'Colmain, C. C. Klaver et al., "Causes and prevalence of visual impairment among adults in the United States," Archives of Ophthalmology, vol. 122, no. 4, pp. 477485, 2004.

[3] C. Bunce and R. Wormald, "Causes of blind certifications in England and Wales: April 1999-March 2000," Eye, vol. 22, no. 7, pp. 905-911, 2008.

[4] W. Smith, J. Assink, R. Klein et al., "Risk factors for age-related macular degeneration: pooled findings from three continents," Ophthalmology, vol. 108, no. 4, pp. 697-704, 2001.

[5] L. M. Weih, M. R. VanNewkirk, C. A. McCarty, and H. R. Taylor, "Age-specific causes of bilateral visual impairment," Archives of Ophthalmology, vol. 118, no. 2, pp. 264-269, 2000.

[6] E. S. Gragoudas, A. P. Adamis, E. T. Cunningham Jr. et al., "Pegaptanib for neovascular age-related macular degeneration," The New England Journal of Medicine, vol. 351, no. 27, pp. 2805-2816, 2004.

[7] N. Ferrara, L. Damico, N. Shams, H. Lowman, and R. Kim, "Development of ranibizumab, an anti-vascular endothelial growth factor antigen binding fragment, as therapy for neovascular age-related macular degeneration," Retina, vol. 26, no. 8, pp. 859-870, 2006.

[8] P. J. Rosenfeld, D. M. Brown, J. S. Heier et al., "Ranibizumab for neovascular age-related macular degeneration," The New England Journal of Medicine, vol. 355, no. 14, pp. 1419-1431, 2006.

[9] N. M. Bressler, T. S. Chang, J. T. Fine et al., "Improved visionrelated function after ranibizumab vs photodynamic therapy: a randomized clinical trial," Archives of Ophthalmology, vol. 127, no. 1, pp. 13-21, 2009.

[10] S. P. Harding, "Neovascular age-related macular degeneration: decision making and optimal management," Eye, vol. 24, no. 3, pp. 497-505, 2010.

[11] P. Mitchell, J. F. Korobelnik, P. Lanzetta et al., "Ranibizumab (Lucentis) in neovascular age-related macular degeneration: evidence from clinical trials," British Journal of Ophthalmology, vol. 94, no. 1, pp. 2-13, 2010.
[12] D. M. Brown and C. D. Regillo, "Anti-VEGF agents in the treatment of neovascular age-related macular degeneration: applying clinical trial results to the treatment of everyday patients," American Journal of Ophthalmology, vol. 144, no. 4, pp. 627-637, 2007.

[13] A. E. Fung, G. A. Lalwani, P. J. Rosenfeld et al., "An optical coherence tomography-guided, variable dosing regimen with intravitreal ranibizumab (Lucentis) for neovascular agerelated macular degeneration," American Journal of Ophthalmology, vol. 143, no. 4, pp. 566-583, 2007.

[14] L. Spielberg and A. Leys, "Treatment of neovascular agerelated macular degeneration with a variable ranibizumab dosing regimen and one-time reduced-fluence photodynamic therapy: the TORPEDO trial at 2 years," Graefe's Archive for Clinical and Experimental Ophthalmology, vol. 246, no. 7, pp. 943-956, 2010.

[15] I. Mantel, L. Zografos, and A. Ambresin, "Early clinical experience with ranibizumab for occult and minimally classic neovascular membranes in age-related macular degeneration," Ophthalmologica, vol. 222, no. 5, pp. 321-323, 2008.

[16] B. J. Ernst, A. J. Barkmeier, and L. Akduman, "Optical coherence tomography-based intravitreal ranibizumab (Lucentis) for neovascular age-related macular degeneration," International Ophthalmology, vol. 30, no. 3, pp. 267-270, 2010.

[17] S. Y. Cohen, L. Dubois, R. Tadayoni et al., "Results of oneyear's treatment with ranibizumab for exudative age-related macular degeneration in a clinical setting," American Journal of Ophthalmology, vol. 148, no. 3, pp. 409-413, 2009.

[18] M. Parravano, F. Oddone, M. Tedeschi et al., "Retinal functional changes measured by microperimetry in neovascular age-related macular degeneration patients treated with ranibizumab," Retina, vol. 329, no. 3, pp. 329-334, 2009.

[19] K. Michalova, S. S. Wickremasinghe, T. H. Tan et al., "Ranibizumab treatment for neovascular age-related macular degeneration: from randomized trials to clinical practice," Eye, vol. 23, no. 8, pp. 1633-1640, 2009.

[20] G. Querques, S. Azrya, D. Martinelli et al., "Ranibizumab for exudative age-related macular degeneration: 24-month outcomes from a single-centre institutional setting," British Journal of Ophthalmology, vol. 94, no. 3, pp. 292-296, 2010.

[21] H. Dadgostar, A. A. C. M. Ventura, J. Y. Chung, S. Sharma, and P. K. Kaiser, "Evaluation of injection frequency and visual acuity outcomes for ranibizumab monotherapy in exudative age-related macular degeneration," Ophthalmology, vol. 116, no. 9, pp. 1740-1747, 2009.

[22] D. F. Martin, M. G. Maguire, G. S. Ying et al., "Ranibizumab and bevacizumab for neovascular age-related macular degeneration," The New England Journal of Medicine, vol. 364, no. 20, pp. 1897-1908, 2011.

[23] C. M. Mangione, P. P. Lee, P. R. Gutierrez et al., "Development of the 25-item national eye institute visual function questionnaire," Archives of Ophthalmology, vol. 119, no. 7, pp. 10501058, 2001.

[24] D. Sheskin, Handbook of Parametric and Nonparametric Statistical Procedures, CRC Press, Boca Raton, Fla, USA, 1996.

[25] D. M. Brown, M. Michels, P. K. Kaiser et al., "Ranibizumab versus verteporfin photodynamic therapy for neovascular age-related macular degeneration: two-year results of the ANCHOR study," Ophthalmology, vol. 116, no. 1, pp. 57-65, 2009.

[26] M. Funk, D. Karl, M. Georgopoulos et al., "Neovascular agerelated macular degeneration: intraocular cytokines and growth factors and the influence of therapy with ranibizumab," Ophthalmology, vol. 116, no. 12, pp. 2393-2399, 2009. 
[27] C. D. Regillo, D. M. Brown, P. Abraham et al., "Randomized, double-masked, sham-controlled trial of ranibizumab for neovascular age-related macular degeneration: PIER study year 1," American Journal of Ophthalmology, vol. 145, no. 2, pp. 239-248, 2008.

[28] P. Abraham, H. Yue, and L. Wilson, "Randomized, doublemasked, sham-controlled trial of ranibizumab for neovascular age-related macular degeneration: PIER study year 2," American Journal of Ophthalmology, vol. 150, no. 3, pp. 315.e1324.e1, 2010.

[29] O. P. Gupta, G. Shienbaum, A. H. Patel, C. Fecarotta, R. S. Kaiser, and C. D. Regillo, "A treat and extend regimen using ranibizumab for neovascular age-related macular degeneration: clinical and economic impact," Ophthalmology, vol. 117, no. 11, pp. 2134-2140, 2010.

[30] M. Bolz and U. Schmidt-Erfurth, "Ranibizumab EXCITE study: exploring the value of optical coherence tomography for the management of ranibizumab therapy in age-related macular degeneration," in Proceedings of the 8th European Society of Retina Specialists Congress (EURETINA '08), Vienna, Austria, May 2008.

[31] G. A. Lalwani, P. J. Rosenfeld, A. E. Fung et al., "A variabledosing regimen with intravitreal ranibizumab for neovascular age-related macular degeneration: year 2 of the PrONTO study," American Journal of Ophthalmology, vol. 148, no. 1, pp. 43-58, 2009.

[32] M. Engelbert, S. A. Zweifel, and K. B. Freund, "“Treat and extend" dosing of intravitreal antivascular endothelial growth factor therapy for type 3 neovascularization/retinal angiomatous proliferation," Retina, vol. 29, no. 10, pp. 14241431, 2009.

[33] F. G. Holz, J. F. Korobelnik, P. Lanzetta et al., "The effects of a flexible visual acuity-driven ranibizumab treatment regimen in age-related macular degeneration: outcomes of a drug and disease model," Investigative Ophthalmology \& Visual Science, vol. 51, no. 1, pp. 405-412, 2010.

[34] S. P. Rothenbuehler, D. Waeber, C. K. Brinkmann, S. Wolf, and U. E. K. Wolf-Schnurrbusch, "Effects of ranibizumab in patients with subfoveal choroidal neovascularization attributable to age-related macular degeneration," American Journal of Ophthalmology, vol. 147, no. 5, pp. 831-837, 2009.

[35] P. K. Kaiser, "Prospective evaluation of visual acuity assessment: a comparison of Snellen versus ETDRS charts in clinical practice (An AOS Thesis)," Transactions of the American Ophthalmological Society, vol. 107, pp. 311-324, 2009.

[36] D. S. Boyer, J. S. Heier, D. M. Brown, S. F. Francom, T. Ianchulev, and R. G. Rubio, "A phase IIIb study to evaluate the safety of ranibizumab in subjects with neovascular agerelated macular degeneration," Ophthalmology, vol. 116, no. 9, pp. 1731-1739, 2009.

[37] S. J. Bakri, M. R. Snyder, J. M. Reid, J. S. Pulido, M. K. Ezzat, and R. J. Singh, "Pharmacokinetics of Intravitreal ranibizumab (Lucentis)," Ophthalmology, vol. 114, no. 12, pp. 2179-2182, 2007.

[38] J. Gaudreault, D. Fei, J. C. Beyer et al., "Pharmacokinetics and retinal distribution of ranibizumab, a humanized antibody fragment directed against VEGF-A, following intravitreal administration in rabbits," Retina, vol. 27, no. 9, pp. 12601266, 2007. 


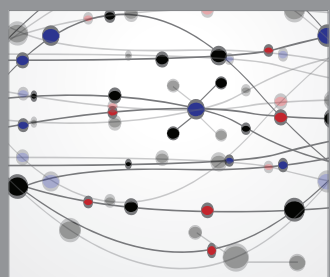

The Scientific World Journal
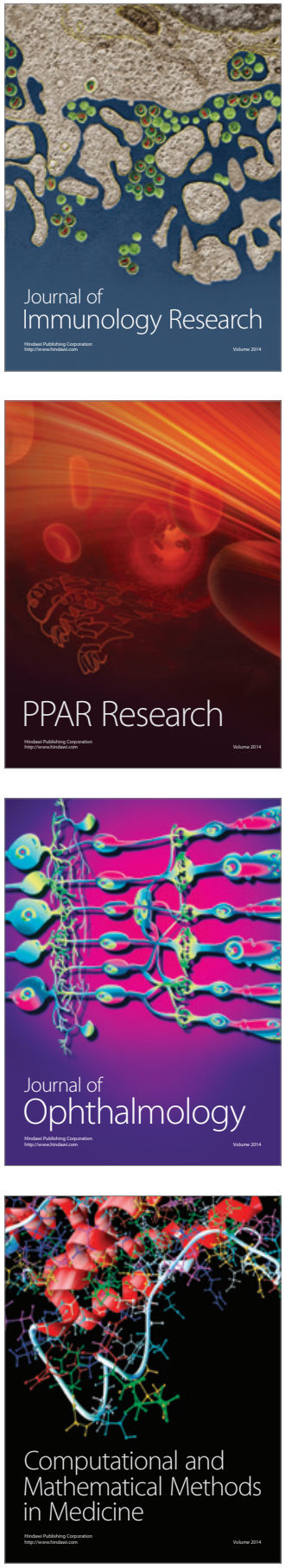

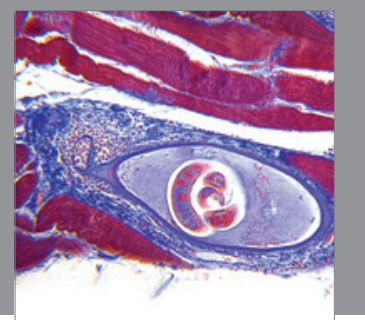

Gastroenterology

Research and Practice
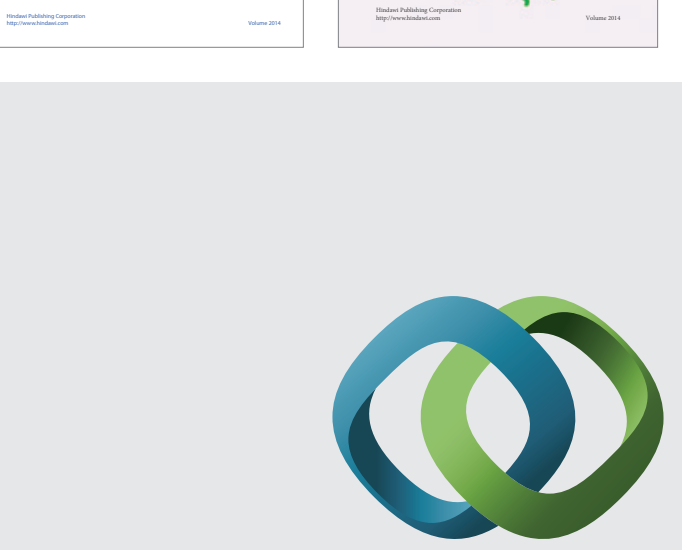

\section{Hindawi}

Submit your manuscripts at

http://www.hindawi.com
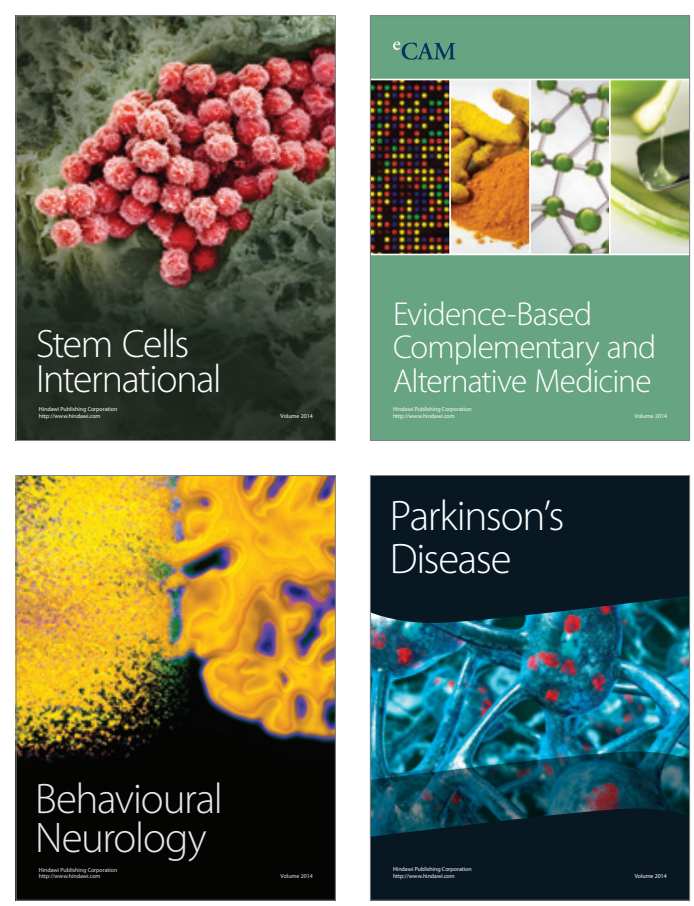

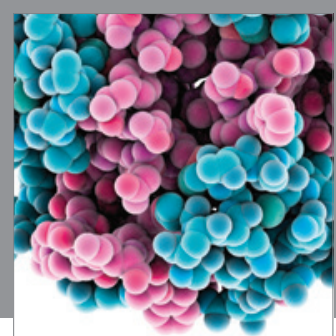

Journal of
Diabetes Research

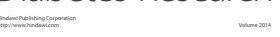

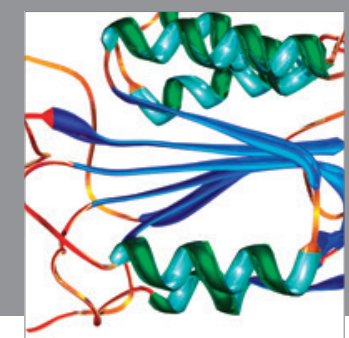

Disease Markers
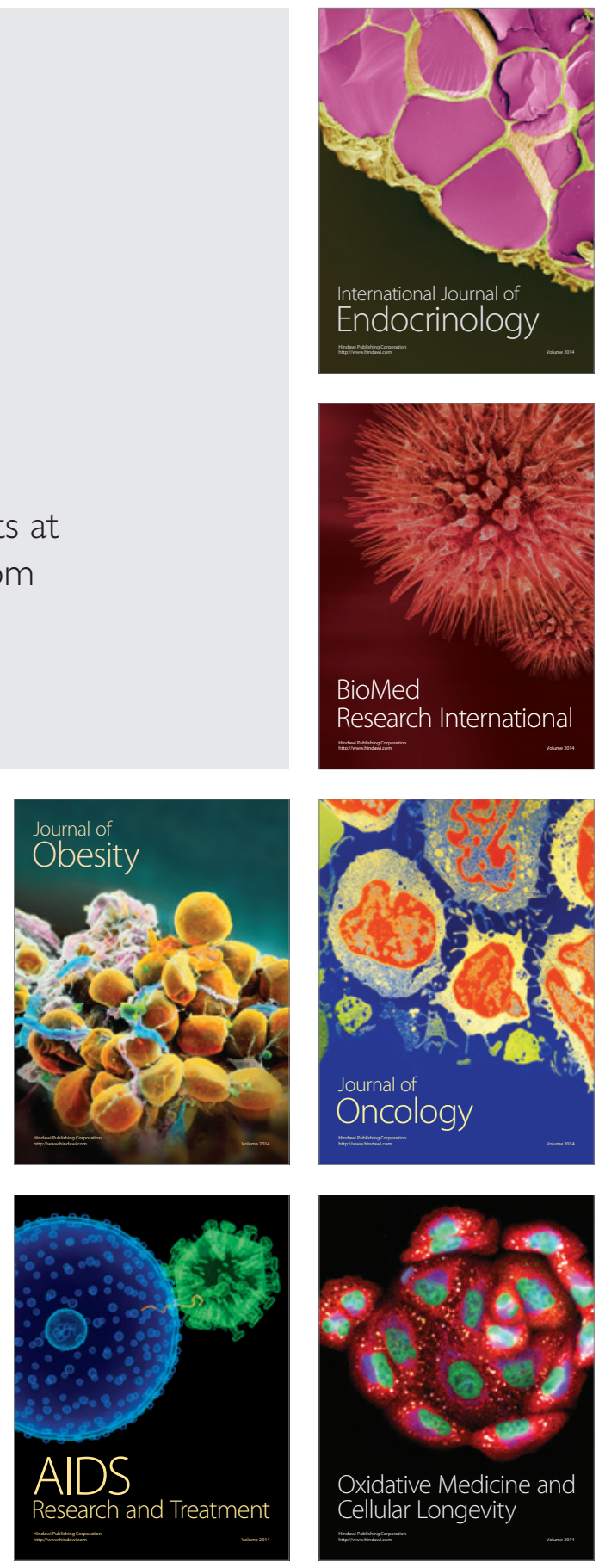